\title{
CULTURAL CRINGE OR LESSONS FOR AUSTRALIAN LEGAL EDUCATION?
}

\author{
JOHN GOLDRING
}

Blackstone's Tower: The English Law School, London, Stevens \& Sons/Sweet \& Maxwell, 1994; Geoffey P Wilson, ed Frontiers of Legal Scholarship: Twenty five years of Warwick Law School, Chichester, John Wiley \& Sons, 1995.

Australia is now developing its own tradition of legal education, as well as its own variant of the common law. Legal education in Australia originated in the demand by the practising legal professions in the various colonies for academic credentials which would increase their status, rather than in more scholarly aspirations. For this reason it has long been different from English legal education, though both focussed on a body of knowledge centred around rules, practices and institutions which had clearly English origins and retained them until quite recently

Should Australians (and specifically, Australian law teachers) be interested in two books which examine and provide examples of legal scholarship in England? Perhaps the most striking thing about the two books on English Law Schools is that in both I found only three mentions of teaching method, as distinct from matters of curriculum or scholarship. The clearest reference is in Michael Chesterman’s essay "Legal Explorations in Different Lands". Chesterman was until recently Dean of Law at the University of NSW, the first Australian law school to question traditional curriculum or teaching methods. He compares the challenge posed respectively by Warwick and UNSW to established traditions; that of Warwick lay in the content of its curriculum, that of UNSW in its methods of teaching. Twining, in his Hamlyn Lectures, refers to instruction in skills (in which he has been a pioneer) as part of an argument that the English Law School curriculum might become more comprehensive, and Wilson, in his rather depressing concluding essay, "Enriching the Study of Law", mentions it in a similar context.

One might wonder why two enlightened and interesting discussions of law schools should omit any more significant references to what some would consider the major justification and a principal activity of law schools. Does this mean that teaching is a neglected activity in English law schools? What can an Australian law teacher learn from these two accounts? There is no question that both books inform and stimulate on the subject of legal scholarship, but say little about how law is learnt and taught in England.

Most lawyers — practising and academic — would find anything written by William Twining worth reading. He is certainly not the first legal academic asked to deliver the Hamlyn Lectures, but is the first to take the opportunity to look at the current state of English law schools and the scholarship that goes on in them. His 1994 Hamlyn lectures are characterised by an erudition and perspicacity, which, though at times expressed idiosyncratically, are of a quality with few competitors in contemporary legal literature. They meet the standards one has come to expect of Twining, and one does learn a great deal about English law schools and what happens in them, especially from a paradigm those familiar with his writing on legal education would have met before - the law school 
at the University of Rutland. Twining's description of this law school illustrates his lectures, though one is left with his assumption that what goes on in the classrooms at Rutland is a very traditional mix of lectures and tutorials.

Twining was identified with Warwick Law School for a long time — from 1972 until 1982 — and served as Chairman for three years. He is a contributor to the 25th Anniversary volume. In many ways both he and Geoffrey Wilson typify the Warwick ethos. Twining was a product of Oxford, Wilson of Cambridge; both felt that something was seriously wrong with the English legal scholarship they encountered as undergraduates. Wilson was appointed to establish the Warwick Law School; those he appointed to the staff there shared his view that a different approach was needed. He looked beyond the traditional Oxbridge breeding grounds of English law teachers, and several Australians, Americans and Canadians found niches at Warwick, at least temporarily. Many have contributed to this volume. Several contributors who have spent significant parts of their careers at Warwick are or have been influential in Australia: Patrick Atiyah at the ANU in the early 1970s; David Farrier at UNSW and Wollongong since 1980; Martin Partington on several visits to UNSW; John Dwyer, now at Griffith; and two of the handful of outstanding contemporary Australian legal scholars, Michael Chesterman, and Ross Cranston, whose value was not rewarded, even if it was recognised, by ANU during the decade Cranston spent there.

Many of the Warwick staff (Twining, Chesterman, Farrier, Atiyah, Ghai, Picciotto and Patrick McAuslan, a stalwart and significant influence at Warwick, though unfortunately not a contributor to this volume) had the salutary experience of teaching in the developing countries of Africa. If they had not previously entertained questions about the relationship between law, legal scholarship and human experience, the challenge of teaching a legal system founded on English common law to students from an entirely different cultural background would have raised them.

Indeed, questions about law and human experience became the focus of legal scholarship at Warwick, and subsequently at other English law schools. Warwick, as Cranston and Chesterman point out, did set out to be different, but remained pluralist; no one group or individual ever asserted that it possessed the correct "line" or theory, nor were there attempts to coerce scholars, as has been the case at other new and "different" law schools. Warwick has remained different and pluralist, accommodating a range of scholarship from Atiyah's almost neo-classical economic history of contract law and its commercial context, through Twining's seminal work in jurisprudence and evidence, Cranston's, Chesterman's, Anderman's, Partington's and McAuslan's new perspectives on a range of areas of legal activity: consumer law, trusts, labour law, land law, social security entitlements and administrative law to a range of Marxist and radical scholarship by scholars like Ghai and Picciotto. The linking theme was a rejection of "black-letter law" approaches. The Warwick scholars considered that it was not enough to learn the rules without learning to appreciate them in their social context.

Unfortunately, there was little legal material to support this approach, so the Warwick staff had to produce it. It was no accident that Warwick staff (Twining and McAuslan, particularly) were influential in setting up at least two new series of legal (or socio-legal) texts (one of them, as Twining points out in Blackstone's Tower, published originally by Weidenfeld and Nicolson, thus breaking the duopoly of Butterworths and Sweet \& Maxwell, a duopoly that severely restricted what legal academics wrote and how they wrote it.) The "Law in Context" series includes a number of modern classics: eg Atiyah's Accidents, Compensation and the Law, Twining and Miers' How to Do Things with Rules, Chesterman's Trusts, Charities and Social Welfare, Cranston's Consumers and the Law and McAuslan's Land, Law and Planning. All of these had their roots either directly in the Warwick curriculum or in some manifestation of the Warwick ethos.

Many of the essays in the collection edited by Wilson represent the fruits of this type of scholarship: Dewar, Farrier, Snyder, Loughlin, Anderman, Picciotto and Ghai write in their special areas of scholarship, but in ways that demonstrate the broad, contextual approach and how it enriches 
and enhances more traditional and doctrinal scholarship. When they do undertake doctrinal work, it is clear that they are at least as competent as scholars who take a narrower and more traditional approach.

Although Warwick did attract at least two women who have made significant contributions to scholarship (Jill Cotterell and Ann Stewart) none of the contributions in this volume are written by women or consider women as a section of the community deserving special attention - even if only because they have been ignored or disregarded by law schools and law teachers in the past.

Trying to study — and presumably teach — law in context must lead a scholar to question his or her purposes. The more general essays in the Wilson book, and much of Twining's, focus on the question of what it is to be an Anglophone legal scholar today. When Wilson first wrote about the Warwick Law School, in 1969 JSTPL, he called the article "Getting on with the job". It was a plea to legal academics to allow the new school to do things differently. The new law school was setting out to challenge assumptions - about law and about the law school curriculum-and that has remained its scholarly mission.

This questioning approach was almost certain to raise hackles. In his "Reflections on Legal Education", ${ }^{1}$ Otto Kahn- Freund had pointed out the inherent tension in English legal education. On the one hand the culture of English law is one of deference to authority. Solicitors, barristers and academics defer to the judges; in their judicial work the judges defer to the authority of precedent. The academic culture, on the other hand, centres around the questioning of assumptions. Both these representations are, of course, ideal types which may not reflect what actually happens. Kahn-Freund, an English legal academic with a background in the German intellectual tradition, was probably one of the few who could have pointed this out without running the risk of being ridiculed. When he wrote, his ideas were regarded by some law teachers as extreme and radical.

Legal education is, however, firmly situated in the university. England and New South Wales are probably the only two places left in the world where a university degree in law is not a prerequisite for practice. Even in those places, most entrants to the legal profession now seek a law degree. Many students who do not intend to follow the traditional professional paths (or who, for economic reasons will never do so) also study law. What should they study? Assuming that, because they are located in the University, their teachers should be scholars, what form should their scholarship take?

Both in Blackstone's Tower and in his contribution to the Warwick anniversary volume, a critical appraisal of English legal scholarship following the Hamlyn lectures, called "A Nobel Prize for Law?”, Twining sees four aspects of the legal scholar. Borrowing from Bentham, he sets up the model of the Expositor, who locates and describe legal rules; and the Censor, who criticises rules on the basis of policy and moral arguments. He also uses as models the Scientist, who seeks to arrange rules and practices in rational order; and the Craftsman, who, as a skilled practitioner, manipulates the rules, practices and institutions that make up the law in practical applications. It struck me that absent from this range was the Teacher!

In England, the traditional academic was an Expositor; or possibly a Craftsman. Occasionally one might find a Censor or a Scientist, but these were aberrations. The position has now changed. While the Expositor remains dominant, the Scientist makes a strong challenge (a rather worrying thought, as I shall try to explain below); the critics, typified by the contributors to this book, are also more vocal.

In 25 years universities have changed quite significantly. The legal academic is now under intellectual pressure - pressure which often does not allow for the nature of the discipline of law. Here the parallels between England and Australia are closest, though the responses in the two countries may be different. In this part of his essay Geoffrey Wilson is at his most gloomy His view is that because of external pressures on the University "undergraduates and graduates are no longer the primary customers of law schools.”(227)

The shift of emphasis in universities is from education to research. This may be true in England. Wilson associates this with the need for universities to justify themselves and become accountable to the wider community. Vice-chancellors have turned universities into outposts of the "research 
industry" In Australia, one hopes this is not entirely true. A recent report commissioned by the Australian Committee for the Advancement of University Teaching points out that the rhetoric of Australian Vice-chancellors recognises the political reality that in Australia the justification for public expenditure on universities is primarily undergraduate teaching. ${ }^{2} \mathrm{My}$ impression is that in Australian politics, universities survive only because of their role as training grounds for the professions and in keeping middle-class children off the unemployed lists. Politicians could not give a hoot about research, except for some highly specialised medical and agricultural research — there are very few votes in scholarship. This may be another ground for the stronger emphasis on teaching, at least in some Australian law schools.

However, Australian legal scholars are subject to pressures to emphasise their research, often at the expense of attention to teaching, and this is to be regretted. My view, idiosyncratic though it may be, is that the real fruits of legal scholarship are not found mainly in publications, but in the range of work law graduates are doing 5, 10, or 20 years after they graduate. This is just as much the product of scholarship as abstruse articles in refereed journals; it results from the scholarship of teaching, rather than the scholarship of published research. It is relatively common for the good law teacher, with his or her students, jointly and severally to expand the boundaries of legal knowledge in the course of their learning activities. Knowledge and understanding of law is most important where it is applied, and scholarship reflected in good learning and teaching is therefore paramount.

That view will not satisfy Vice-chancellors or promotions committees either in England or Australia. The prevailing ethos of universities, even in Australia, is becoming more Scientific, and that the rather irrational nature of the common law, as well as the professional ethos of Australian legal education, make the life of legal scholars more difficult in such an environment. If legal scholars are not to be Expositors, what are they to do? The pressure is for them to be Scientists, and Wilson, whose familiarity with the German legal system and its different cultural tradition is apparent, seems to regret that law is not and cannot be a science, even a social science. (p237) He describes the attempts by English scholars to develop socio-legal studies - an issue considered in more detail by Partington's essay Twining is more optimistic or possibly realistic, for in “A Nobel Prize for Law" he sees a strong future for legal scholarship, even if not of the traditional kind.

Legal scholarship in the common law world has often been subjected to the criticism that it is "atheoretical". The elevation of the Scientist to the academic pantheon increases the pressure on legal academics to be more "theoretical", and this pressure has manifested itself, in the United States and elsewhere, in the Critical Legal Studies (“CLS”) and Law and Economics (“LE”) Movements. Cranston points out that legal scholarship must be founded in law and that "a ... problem with theory is that it, rather than law, can become the organising charter of the academic's work (13-14). This approach to the place of theory represents perhaps the strongest, and in my view, most beneficial, influence of the Warwick-led reforms on modern legal scholarship. Neither CLS nor LE has taken root in England as it has in North America, possibly because English legal academics have not felt the same need for a theoretical crutch, possibly because the intellectual culture and climate in England is more tolerant and pluralistic. The Warwick legal scholars, including most of those represented in the anniversary collection, have not lacked ideological commitment, but this has not necessarily shaped their legal scholarship so that it ceases to be grounded in law. Partington and Wilson deal with the difficulties of drawing on other disciplines, especially sociology, to team about law, but the Warwick law school has produced scholars who show that this can be done usefully. It has also nurtured Twining, whose contribution to legal theory is highly significant.

The other major influence on English legal education is the fact that Britain is now part of Europe, and English law is now increasingly a sub-species of European law, though still distinct. ${ }^{3}$ An Australian reading either book cannot but be impressed by the way this changed has influenced the curriculum of English law schools. English legal academics - Snyder being an exception - were a little slow to realise the impact Europeanisation would have on their legal system and heritage. That has now 
changed, and the parochialism which has typified English law and English legal scholarship is now a thing of the past. It may be a challenge for Australian legal academics to cope with the impact of globalisation of trade and culture on Australian law in the absence of any formal legal structures which make Australia part of a wider community. International law, even the trade, environmental and human rights aspect of international law which have the most direct impact on national legal system have not yet done this in Australia beyond those lawyers and legal academics directly affected. Australian lawyers can and should learn from England about the necessity of a wider perspective on the study of law at all levels.

As an Australian law teacher who spent some time at Warwick in the 1970s and was profoundly influenced by the experience and subsequent friendship with and guidance from William Twining, and who has subsequently had the responsibility and pleasure of building a new law school, I had a predisposition to find both these books rewarding. I was disappointed in some aspects, not least the absence of attention to student learning. However, there is a great deal worthwhile that Australian lawyers can gain from these books, even if it is only a mild glow of self-satisfaction at what has been achieved in some Australian law schools.

(C)1996. (1996) 7 Legal Educ Rev 125.

1 (1966) 29 MLR 121.

2 P Ramsden, et al, Recognising and Rewarding Teaching in Australian Universities, Canberra, Committee for the Advancement of University Teaching, 1995.

3 Hodgson (1995) Web JCL provides some interesting and complementary reflections. 